\title{
Level of Hardiness and Physical Illness of Working Women
}

\author{
Mrs. Reena George ${ }^{1 *}$, Dr. S. Raju², Mr. Sajithkumar. $\mathrm{P}^{3}$
}

Keywords: Hardiness, Physical Illness, Working Women

Stress is a part and parcel of everybody's life. Though it is both men and women who deal with stress, particularly the working women who tend to be its most common victims. Majority (80\%) of the Indian women experiences stress because of sex-specific job stressors and difficulties combining work and family.

In this era women are expected to be the competitive workers in par with men in organizations than continuing to be part there for name sake. They need to perform extremely well in order to keep their job place and put their all efforts to maintain the balance between family and job. They experience a lot of indescribable stress and strain. Some of them express it through their behaviour toward subordinates, children and other neutral objects. Whereas some of them manage their time well and become productive in their organization and in family.

The reaction to stress is determined by one's personality traits. Kobasa (1992) observed that some individuals possess an ability to withstand stress known as 'Hardiness'. Hardy persons are those who are deeply committed to themselves and the activity within their daily lives; believe that they can control the events they experience, view life change as an exciting challenge for further growth instead as a threat.People who possess high level of hardiness are free from stress related ailments. This study intended to bring attention of all the mental health care professionals to educate the society to protect their women in order to maintain their own mental health and build a healthy family and thereby a healthy society.

\section{STATEMENT OF THE PROBLEM}

A study to determine the level of Hardiness and physical illness of working women in selected community of Kozhikode District, Kerala

\footnotetext{
${ }^{1}$ Dept. of Research \&Development, Bharathiar University, NAAC accredited with 'A' grade), Associate Professor \& Head, Dept. of Mental Health Nursing, Malabar Institute of Medical Sciences, Kozhikode

${ }^{2}$ Associate Professor \& Former Head, Dept. of Psychology, Kerala University, Trivandrum

${ }^{3}$ Research Scholar, INC Consortium \& Assistant Professor in Government College of Nursing, Kozhikode. *Corresponding Author

(C) 2015 I R George, S Raju, Sajithkumar. P; licensee IJIP. This is an Open Access Research distributed under the terms of the Creative Commons Attribution License (http://creativecommons.org/licenses/by/2.0), which permits unrestricted use, distribution, and reproduction in any Medium, provided the original work is properly cited.
} 


\section{Objectives of the study were to:}

- Determine the level of Hardiness among workingwomen as measured by Hardiness assessment Scale.

- Identify the association between the level of hardiness and selected demographic variables.

- Identify the association between level of hardiness and physical illness among working women

\section{METHOD}

Quantitative non-experimental approach with Descriptive Survey Design was selected for study. The sample consisted of 72 working women who had the education level between plus two and post graduation. The Participants were selected through purposive sampling technique. The study includes, Women who have been working in the organization from a period from 1 year to 20 years. Women who were staying in the family and in the age group of 20- 50 years. The study excludes the Women who had maids at home for help and women who were staying in the hostel. The collected data were analyzed using descriptive and inferential statistics using SPSS version 17.

\section{Data Collection Tools and Technique}

The tools were demographic proforma and hardiness scale. The technique used was self reporting.

\section{Data Analysis}

The collected data were analyzed using descriptive and inferential statistics using SPSS version 17.

\section{RESULT}

Distribution of sample with regard to marital status

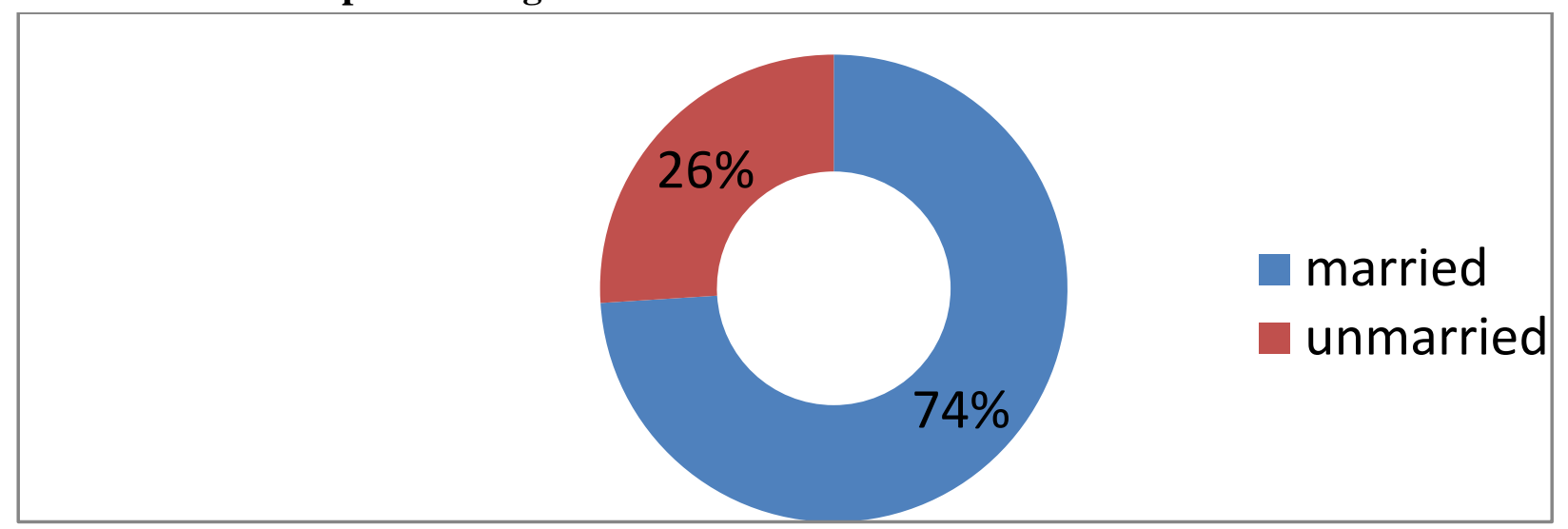




\section{Distribution of sample according to Education and level of Hardiness}

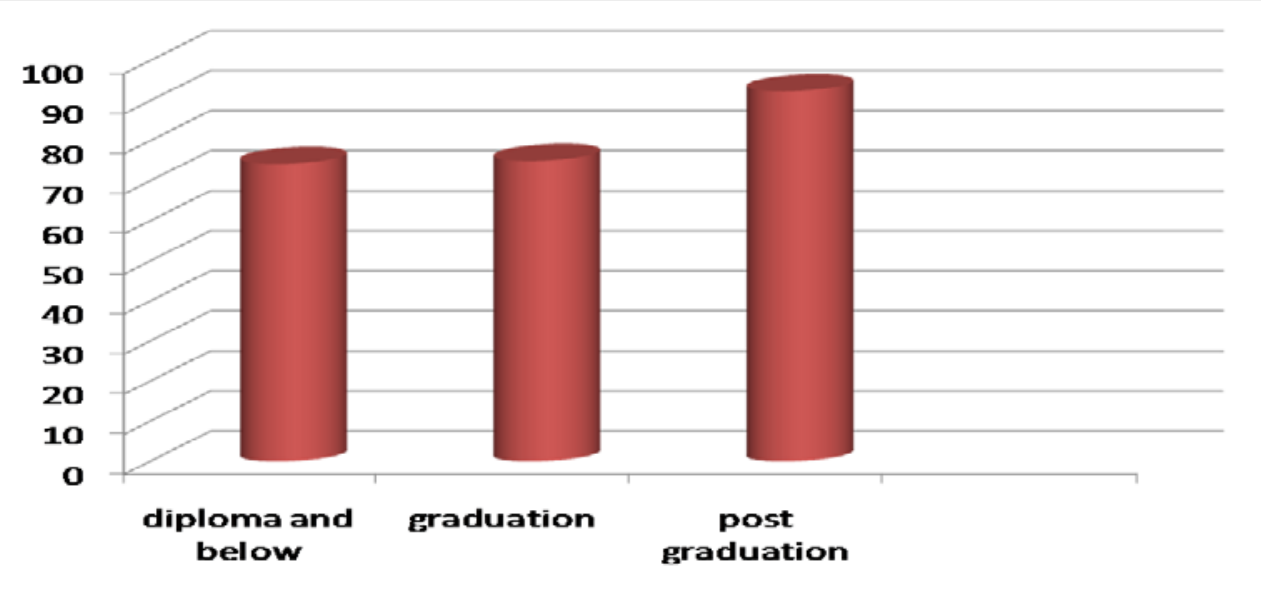

Grading of Hardiness score and presence of physical illness in working women

\begin{tabular}{llllll|}
$\begin{array}{l}\text { Grading of } \\
\text { Hardiness } \\
\text { Score }\end{array}$ & Range & Frequency & Percentage & Mean & $\begin{array}{l}\text { Presence of } \\
\text { physical } \\
\text { illness in \% }\end{array}$ \\
\hline Low & $45-75$ & 6 & $8.34 \%$ & 71 & $66.6 \%$ \\
\hline Moderate & $76-90$ & 42 & $58.33 \%$ & 78 & $42.86 \%$ \\
\hline High & $91-130$ & 24 & $33.33 \%$ & 95 & ------- \\
\hline
\end{tabular}

Among the 6 members whose Hardiness score was low (45-75) 4 of them had the history of chronic physical illness. Out of the 42 working women whose score was in moderate range (7690), 18 of them were experiencing physical illness. The result revealed that among 72 working women $8.3 \%$ ( 6 women)had low level of hardiness and $50 \%$ ( 42 women) had moderate level of Hardiness where as the women belong to high level of hardiness were 33.35\% (24 women). There was no statistically significant association between the hardiness score and some of the variables like age, occupation, duration of employment, marital status and income, whereas The remaining variables like educational qualification and presence of illness had shown significant association between hardiness score at 0.05 level.

\section{INTERPRETATION AND CONCLUSION}

This study has shown that $33.3 \%$ of working women had high level of hardiness and were able to face the stress as a challenge without suffering any physical or mental problem. Hardiness is a trait which can be developed through training. All the institutions have to adapt various inservice education courses to empower their women employees to manage their work, family and 
professional growth effectively. A healthy employee will be an asset to the organization in terms of fulfilling the vision and mission of the organization.

\section{REFERENCE}

Abdullah, R., S. Jahan and S. Saha, 2008. Occupational stress, social and family difficulties and job contentment of working womenJ. Bus. Econ., 3: 139-153.

Maryam Zarra-Nezhad, Ali Moazami-Goodarzi, Leila Hasannejad and Khadijeh Roushani. Occupational Stress and Family Difficulties of Working Women , Iran Current Research in Psychology1 (2): 75-81, 2010

Yahaya, A., N. Yahaya, K. Arshad, J. Ismail and S. Jaalam et al., 2009. Occupational stress and its effects towards the organization management. J. Social science 5: 3 